\title{
BMJ
}

\section{Incidental findings on brain magnetic resonance imaging: systematic review and meta-analysis}

\author{
Zoe Morris, senior clinical fellow in neuroradiology, ${ }^{1}$ William N Whiteley, CSO clinical academic fellow, ${ }^{1}$ \\ W T Longstreth Jr, professor of neurology and epidemiology, ${ }^{2}$ Frank Weber, consultant neurologist, ${ }^{3}$ \\ Yi-Chung Lee, attending physician, ${ }^{4}$ Yoshito Tsushima, associate professor of diagnostic radiology, ${ }^{5}$ \\ Hannah Alphs, medical student, ${ }^{6}$ Susanne C Ladd, consultant radiologist, ${ }^{7}$ Charles Warlow, emeritus \\ professor of medical neurology, ${ }^{1}$ Joanna M Wardlaw, professor of applied neuroimaging, ${ }^{1,8}$ \\ Rustam Al-Shahi Salman, MRC clinician scientist and honorary consultant neurologist ${ }^{1}$
}

${ }^{1}$ Division of Clinical Neurosciences, Western General Hospital, Edinburgh EH4 2XU

${ }^{2}$ Departments of Neurology and Epidemiology, Harborview Medical Center, Seattle, WA, USA

${ }^{3}$ German Air Force Institute of Aviation Medicine, Department of Neurology, Fuerstenfeldbruck, Germany

${ }^{4}$ Department of Neurology, Taipei Veterans General Hospital, Taiwan

${ }^{5}$ Department of Diagnostic Radiology and Nuclear Medicine, Gunma University Hospital, Japan

${ }^{6}$ Department of Radiology and Radiological Sciences, Johns Hopkins Hospital, Baltimore, MD, USA

${ }^{7}$ Department of Diagnostic and Interventional Radiology and Neuroradiology, University Hospital Essen, Germany

${ }^{8}$ SFC Brain Imaging Research Centre, University of Edinburgh Correspondence to: R Al-Shahi Salman Rustam.Al-Shahi@ed.ac.uk

Cite this as: BMJ 2009;339:b3016 doi:10.1136/bmj.b3016

\section{ABSTRACT}

Objective To quantify the prevalence of incidental findings on magnetic resonance imaging (MRI) of the brain.

Design Systematic review and meta-analysis of observational studies.

Data sources Ovid Medline (1950 to May 2008), Embase (1980 to May 2008), and bibliographies of relevant articles.

Review methods Two reviewers sought and assessed studies of people without neurological symptoms who underwent MRI of the brain with or without intravenous contrast for research purposes or for occupational, clinical, or commercial screening.

Main outcome measures Overall disease specific and age specific prevalence of incidental brain findings, calculated by meta-analysis of pooled proportions using DerSimonian-Laird weights in a random effects model.

Results In 16 studies, 135 of 19559 people had neoplastic incidental brain findings (prevalence $0.70 \%$, $95 \%$ confidence interval $0.47 \%$ to $0.98 \%$ ), and prevalence increased with age ( $X^{2}$ for linear trend, $\mathrm{P}=0.003$ ). In 15 studies, 375 of 15559 people had nonneoplastic incidental brain findings (prevalence $2.0 \%$, $1.1 \%$ to $3.1 \%$, excluding white matter hyperintensities,
Incidental brain findings on magnetic resonance imaging

Potentially symptomatic or treatable abnormalities

- Neoplasms

- Cysts

- Structural vascular abnormalities

- Inflammatory lesions

- Other-for example, Chiari malformations, hydrocephalus

Markers of cerebrovascular disease

- White matter hyperintensities

- Silent (asymptomatic) brain infarcts

- Brain microbleeds silent infarcts, and microbleeds). The number of asymptomatic people needed to scan to detect any incidental brain finding was 37 . The prevalence of incidental brain findings was higher in studies using high resolution MRI sequences than in those using standard resolution sequences $(4.3 \% \vee 1.7 \%$, P $<0.001)$. The prevalence of neoplastic incidental brain findings increased with age.

Conclusions Incidental findings on brain MRI are common, prevalence increases with age, and detection is more likely using high resolution MRI sequences than standard resolution sequences. These findings deserve to be mentioned when obtaining informed consent for brain MRI in research and clinical practice but are not sufficient to justify screening healthy asymptomatic people.

\section{INTRODUCTION}

Apparently asymptomatic intracranial abnormalities of potential clinical significance, or incidental brain findings (box), are fast becoming problematic, with the increasing use of magnetic resonance imaging (MRI) of the brain by clinicians, ${ }^{1}$ researchers, ${ }^{2}$ and companies that carry out health "check-ups."

The detection of incidental findings is an unintended consequence of brain MRI in clinical situations where the prevalence of any relevant finding is likely to be low. Detection is potentially detrimental because the treatment can have harmful as well as beneficial consequences. Knowing the chance of discovering incidental brain findings would help clinicians inform patients of these risks, help researchers adequately inform healthy volunteers in imaging research, and adequately inform people who seek screening by brain MRI.

The overall prevalence of incidental brain findings including silent infarcts in a recent study of 2000 volunteers aged 46-97 years using high resolution MRI sequences, without injected contrast or angiographic sequences, was more than $10 \% \cdot{ }^{\text {w1 }}$ However, a systematic review and meta-analysis of the published literature has been recommended ${ }^{4}$ because it could provide 
more precise estimates of the range of incidental findings on brain MRI and explore the influence of study design, patient characteristics, and imaging parameters on the detection of incidental brain findings.

\section{METHODS}

In May 2008 we searched Ovid Medline from 1950 and Embase from 1980 (http://gateway.ovid.com, see web extra appendix 1 for search strategy) for reports on the use of brain MRI in healthy people, volunteers, research controls, and people undergoing commercial, clinical, or occupational screening. We did not restrict the search by language or patients' age. We supplemented the electronic searches with surveillance of electronic tables of contents in neurological journals and by hand searching the bibliographies of pertinent articles. Two authors (ZM and WNW or RA-SS) read the title and abstract of every study identified by the electronic searches and critically appraised the full text of potentially eligible studies.

We defined incidental brain findings as apparently asymptomatic intracranial abnormalities that were clinically significant because of their potential to cause symptoms or influence treatment. We divided the findings into two clinically relevant categories: neoplastic (benign and malignant tumours) and non-neoplastic (cysts, structural vascular abnormalities, inflammatory lesions, and "other" such as hydrocephalus, Arnold-Chiari malformations, and extra-axial collections). Although white matter hyperintensities, silent brain infarcts or lacune, and brain microbleeds are incidental findings, we did not focus on them because of their known increasing prevalence with age, ${ }^{56}$ their largely unknown role in causing symptoms, and the current uncertainty about whether or not to institute primary prevention after their detection. ${ }^{6}$ We distinguished incidental brain findings from normal variants, which we defined as anatomical variants that do not have the potential to cause symptoms - for example, cavum septi pellucidi, large cisterna magna, and ventricular asymmetry.

We included studies published in full that reported the prevalence of incidental brain findings in people without neurological or psychiatric symptoms, who underwent brain MRI as research cases or controls or as recipients of commercial, clinical, or occupational screening. We did not include studies restricted to markers of cerebrovascular disease because they have recently been the subject of systematic reviews. ${ }^{56}$ Disagreements about study eligibility were resolved by discussion, or arbitration by one author (RA-SS). If several publications arose from the same cohort, we only included the largest study.

\section{Data extraction}

Two authors extracted data on study design, population characteristics, and MRI parameters from each study, and extracted the overall and age specific frequencies of each type of incidental brain finding. When age specific data on prevalence were not provided in an original publication we requested these by emailing the corresponding author, who became a coauthor of this review if they extracted and supplied data.

\section{Data analysis}

We carried out a meta-analysis of prevalence data for each incidental brain finding and all incidental brain findings (excluding markers of cerebrovascular disease), using data from the studies that enabled relevant calculations. We used the $\mathrm{I}^{2}$ statistic to estimate the heterogeneity of individual studies contributing to the pooled estimate, and determined whether to use a fixed or random effects model on this basis. We calculated the pooled proportion as the back transform of the weighted mean of the transformed proportions, using DerSimonian-Laird weights in a random effects model, ${ }^{7}$ and report $95 \%$ confidence intervals. We did subgroup analyses to explore the influence of the MRI sequences used, the specialty of the person reporting on the MRI, and participant characteristics on the pooled prevalence of all incidental brain findings (excluding markers of cerebrovascular disease). When age specific data were provided in the original publications or made available to us on request, we calculated age specific prevalence in 20 year age bands because 10 year age bands contained insufficient data. The number of asymptomatic people needed to scan to detect one incidental brain finding, or number needed to scan, was the reciprocal of the prevalence estimate. We used Confidence Interval Analysis v2.1.2 to calculate $95 \%$ confidence intervals, and StatsDirect v2.7.2 for $\chi^{2}$ tests for trend, tests of heterogeneity, and meta-analysis of proportions with random effects models.

\section{RESULTS}

The electronic search strategy identified 1862 publications, of which 19 papers reporting data on 17 cohorts were eligible..$^{8-10 \text { w1-w16 }}$ We excluded three publications because they reported on cohorts included in this systematic review at earlier stages in their recruitment, ${ }^{89}$ or because it was difficult to be certain that most participants were asymptomatic for neurological conditions. ${ }^{10}$

We included 16 publications reporting data between 1989 and 2008 on 16 unique cohorts (19559 people) from Asia (n=7277), w5 w10 w15 Europe (n=5942), ${ }^{w 1}$ w2 w9 w11 w14 the United States $(\mathrm{n}=5764),{ }^{\mathrm{w} 3} \mathrm{w} 4 \mathrm{w} 7 \mathrm{w} 8 \mathrm{w12}$ w13 and Australia $(\mathrm{n}=576)^{\mathrm{w} 6 \mathrm{w} 16}$ who had undergone brain MRI (table). ${ }^{\text {w1-w16 }}$ The number of people in each study ranged from 60 to 4000 , with a mean age of 11 to 63 years (range 1-97 years). One study included cases $(\mathrm{n}=589)$ and controls $(\mathrm{n}=67),{ }^{\mathrm{w} 12}$ but in the rest participants were exclusively controls (six studies, $\mathrm{n}=1702$ ), ${ }^{\mathrm{w} 2} \mathrm{w} 4 \mathrm{w6}-\mathrm{w} 8 \mathrm{w13}$ cases (three studies, $\mathrm{n}=6739$ ), ${ }^{\mathrm{w1}}$ w3 $w_{16}$ or screening attendees (six studies, $n=11118$ ). ${ }^{\mathrm{w} 5}$ w9-w11 w14 w15

\section{Critical appraisal}

Participants had comorbidities in four studies, such as hypertension, ${ }^{\mathrm{w} 9 \mathrm{w} 10 \mathrm{w} 12}$ diabetes mellitus, ${ }^{\mathrm{w} 9 \mathrm{w} 10}$ myocardial 
Table 1|Details of included studies

\begin{tabular}{|c|c|c|c|c|c|c|c|c|}
\hline Study & Country & $\begin{array}{c}\text { Total } \\
\text { sample size }\end{array}$ & $\begin{array}{l}\text { Mean (range) } \\
\text { age (years) }\end{array}$ & $\%$ male & Reason for imaging & Comorbidities & $\begin{array}{l}\text { Normal or normal } \\
\text { variants defined }\end{array}$ & $\begin{array}{c}\text { Specialty } \\
\text { of scan readers }\end{array}$ \\
\hline Wahlund $1989^{\text {w2 }}$ & Sweden & 101 & NS (NS) & NS & Research controls & Absent & No & NS \\
\hline Yue $1997^{\text {w3 }}$ & USA & 3672 & NS ( $\geq 65)$ & NS & Research cases & NS & No & Neuroradiologist \\
\hline Katzman $1999^{\text {w4 }}$ & USA & 1000 & $29(3-83)$ & 55 & Research controls & Absent & Yes & Neuroradiologist \\
\hline Onizuka $2001^{\text {w5 }}$ & Japan & 4000 & $56(24-85)$ & 50 & Commercial or clinical screening & NS & No & NS \\
\hline Lubman $2002^{\text {w6 }}$ & Australia & 98 & 27 (NS) & 63 & Research controls & Absent & Yes & Neuroradiologist \\
\hline $\operatorname{Kim} 2002^{\mathrm{w} 7}$ & USA & 225 & $11(0-18)$ & 44 & Research controls & Absent & No & Neuroradiologist \\
\hline Illes $2004^{\text {w8 }}$ & USA & 151 & $47(18-90)$ & 54 & Research controls & Absent & No & Neuroradiologist \\
\hline Goehde $2005^{\text {w9 }}$ & Germany & 298 & $50(31-73)$ & 83 & Commercial or clinical screening & Present & No & Neuroradiologist \\
\hline Tsushima $2005^{\mathrm{w} 10}$ & Japan & 1113 & $53(22-84)$ & 68 & Commercial or clinical screening & Present & No & General radiologist \\
\hline Weber $2006^{\text {w11 }}$ & Germany & 2536 & $21(17-35)$ & 100 & Occupational screening & Absent & No & General radiologist \\
\hline Alphs $2006^{\text {w12 }}$ & USA & 656 & $61(35-82)$ & 100 & Research cases and controls & Present & No & Neuroradiologist \\
\hline Kumra $2006^{\text {w13 }}$ & USA & 60 & NS (10-21) & NS & Research controls & Absent & No & Neuroradiologist \\
\hline Baumgart $2007^{\mathrm{w} 14}$ & Germany & 1007 & $55(40-67)$ & 71 & Commercial or clinical screening & Present & No & General radiologist \\
\hline Vernooij $2007^{\mathrm{w} 1}$ & Netherlands & 2000 & $63(46-97)$ & 48 & Research cases & NS & Yes & $\begin{array}{l}\text { Neuroradiologist } \\
\text { or neurologist }\end{array}$ \\
\hline Lee $2008^{\mathrm{w} 15}$ & Taiwan & 2164 & $52(17-89)$ & 57 & Commercial or clinical screening & NS & No & $\begin{array}{l}\text { Neuroradiologist } \\
\text { or general radiologist }\end{array}$ \\
\hline Kumar $2008^{\mathrm{w} 16}$ & Australia & 478 & NS (60-64) & 53 & Research cases & NS & No & Neuroradiologist \\
\hline
\end{tabular}

infarction, ${ }^{\mathrm{w} 9 \mathrm{w} 10}$ and hyperlipidaemia, ${ }^{\mathrm{w} 10}$ but they did not seem to have any comorbidities in seven studies, and no comment was made in the remainder (table). The neurological asymptomatic status of participants was determined by history ${ }^{\text {w2 }}$ w6-w8 w12-w14 w16; history and examination $^{\mathrm{w1} \mathrm{w} 3 \mathrm{w} 4 \mathrm{w}{ }^{\mathrm{l} 0}}$; history, examination, and investigation $^{\mathrm{w11}}$; or unspecified means. ${ }^{\mathrm{w} 5 \mathrm{w} 9 \mathrm{w} 15}$ However, 21 $(0.1 \%)$ of the 19559 participants had preceding neurological symptoms that may have been related to abnormalities found on brain MRI. ${ }^{\text {w1w310w16 }}$ No study prespecified the potential incidental brain findings of interest, and almost none was confirmed by pathology. Only three studies defined normal variants (table).

The field strengths of the MRI magnets were reported as 1.0 tesla $^{\mathrm{w} 5 \mathrm{w} 10 \mathrm{w11}}$ or 1.5 tesla, ${ }^{\mathrm{w} 1 \mathrm{w} 3 \mathrm{w} 6 \mathrm{w} 9 \mathrm{w} 13-}$ ${ }^{w 16}$ or not reported. ${ }^{w 2 w 4 w 7 w 8 w 12}$ None of the studies published before 2002 used sequences regarded as high resolution by modern standards (see web extra table on bmj.com), ${ }^{\text {w2-w5 }}$ and most subsequent studies used lower resolution sequences $(5 \mathrm{~mm}$ axial $\mathrm{T} 2$ weighted, axial or sagittal T1 weighted, axial or coronal fluid attenuated inversion recovery, and axial proton density weighted sequences). Some recent studies also included magnetic resonance angiographic sequences, ${ }^{\text {w-w7 }}$ or high resolution sequences such as three dimensional $\mathrm{T} 1$ spoiled or $\mathrm{T} 2 *$ gradient echo, ${ }^{\mathrm{w} 1}$ w6-w8 w11-w13 w16 or high resolution axial proton density or fluid attenuated inversion recovery. Abnormalities on scans were interpreted by neuroradiologists, ${ }^{\text {w3 w4 w6-w9 }}$ ${ }^{\mathrm{w} 12} \mathrm{w}^{13} \mathrm{w} 16$ a neuroradiologist or general radiologist, ${ }^{\mathrm{w} 15}$ a neuroradiologist or neurologist, ${ }^{\mathrm{w} 1}$ general radiologists, ${ }^{\text {w10 w11 w14 }}$ or unspecified observers. ${ }^{\text {w2 w5 }}$

\section{Disease specific and overall prevalence}

Disease specific prevalence was calculable for intracranial neoplasms in all 19559 participants, but one study of 4000 participants only described asymptomatic tumours, ${ }^{\text {w5 }}$ resulting in a denominator of 15559 for prevalence of non-neoplastic incidental brain findings (fig 1). The $\mathrm{I}^{2}$ statistic ranged from $0 \%$ for low grade gliomas and cavernous malformations, to $86 \%$ for arachnoid cysts, indicating variable degrees of heterogeneity among the included studies. We therefore used a random effects model to meta-analyse the data.

The prevalence of neoplastic incidental findings was $0.70 \%$ (95\% confidence $0.47 \%$ to $0.98 \%$ ), but description of the prevalence of each specific tumour type was impaired by either a lack of subtyping ${ }^{\mathrm{w12}}$ or non-specific classifications (for example, cerebellopontine angle tumour, ${ }^{\text {w11 }}$ unclassifiable fourth ventricular tumour, ${ }^{\text {w11 }}$ hamartoma, ${ }^{w 6}$ suprasellar tumour $\left.{ }^{\mathrm{w} 16}\right)$. The prevalence of non-neoplastic incidental findings, excluding markers of cerebrovascular disease, was $2.0 \%(1.1 \%$ to $3.1 \%$; fig 1). Arachnoid cysts were the single most prevalent incidental finding $(0.5 \%, 0.21 \%$ to $0.87 \%)$, followed by aneurysms $(0.35 \%, 0.13 \%$ to $0.67 \%)$. The combined prevalence of neoplastic and non-neoplastic incidental findings was $2.7 \%$ (number needed to scan=37).

\section{Influence of MRI sequences, reporting, and participant characteristics}

The detection of incidental findings (excluding markers of cerebrovascular disease) was higher in studies using at least one high resolution MRI sequence (318/6204; $4.3 \%, 3.0 \%$ to $5.8 \%)^{\text {w1 w6-w8 w11-w13 w16 }}$ than in studies using standard resolution sequences $(176 / 9355 ; 1.7 \%, 1.1 \%$ to $\left.2.4 \%, \chi^{2} \mathrm{P}<0.001\right)$. ${ }^{\text {w2-w4 }}$ w9 w10 w14 w15 The detection of these incidental findings in studies using neuroradiologists to interpret images $(272 / 8340 ; 3.5 \%, 1.8 \%$ to $5.7 \%$ )w1 w3 w4 w6-w9 w12 w13 w15 w16 was not significantly higher than in studies using general radiologists $(144 / 4954 ; 2.3 \%, 0.9 \%$ to $\left.4.4 \%, \chi^{2} \mathrm{P}=0.3\right) .^{\mathrm{w} 10 \mathrm{w} 11 \mathrm{w} 14}$ 
To explore the influence of the source of the participants on prevalence of incidental brain findings, the analyses were restricted to studies using at least one high resolution MRI sequence or three dimensional time of flight magnetic resonance angiography. The prevalence was higher among research cases $(198 / 6150 ; 3.4 \%, 0.9 \%$ to $7.5 \%)$ than among attendees of commercial screening $(105 / 4582 ; 2.0,0.9 \%$ to $3.3 \%)$ and research controls $\left(24 / 1635 ; 1.6 \%, 1.0 \%\right.$ to $2.2 \%, \chi^{2}$, $\mathrm{P}<0.001)$. The overall prevalence did not differ between studies in which comorbidities among participants were present $(89 / 3074 ; 2.9 \%, 2.4 \%$ to $3.6 \%)$, absent $(134 / 4171 ; 3.2 \%, 2.7 \%$ to $3.8 \%)$, or unknown $\left(271 / 8314 ; 3.3 \%, 2.9 \%\right.$ to $\left.3.7 \% ; \chi^{2} \mathrm{P}=0.6\right)$.

\section{Age specific prevalence}

Of the 16 included studies, the original data were no longer available for two (totalling 5000 participants), ${ }^{\text {w4 w5 }}$ one (2000 participants) declined to provide age specific tabular data, ${ }^{\mathrm{w} 1}$ and five (totalling 1582 participants) failed

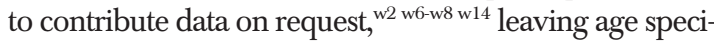
fic grouped summary data on 10977 people, which were provided by six studies ${ }^{\mathrm{w} 3 \mathrm{w} 9 \mathrm{-w} 12 \mathrm{w} 15}$ and extracted from the

\begin{tabular}{|c|c|c|c|c|}
\hline & $\begin{array}{l}\text { Number } \\
\text { with } \\
\text { abnormality }\end{array}$ & $\begin{array}{l}\text { Number } \\
\text { needed } \\
\text { to scan }\end{array}$ & $\begin{array}{l}\text { Prevalence (\%) } \\
\quad(95 \% \mathrm{Cl})\end{array}$ & $\begin{array}{l}\text { Prevalence (\%) } \\
\quad(95 \% \mathrm{Cl})\end{array}$ \\
\hline \multicolumn{5}{|l|}{ Neoplasia ( $n=19$ 559) } \\
\hline Meningioma & 72 & 345 & $\leftarrow$ & $0.29(0.13$ to 0.51$)$ \\
\hline Pituitary adenoma & 27 & 667 & - & 0.15 (0.09 to 0.22$)$ \\
\hline Low grade glioma & 8 & 2000 & - & $0.05(0.02$ to 0.09$)$ \\
\hline Acoustic neuroma & 5 & 3333 & $\cdot$ & 0.03 (0.01 to 0.06$)$ \\
\hline Lipoma & 6 & 2500 & $\cdot$ & $0.04(0.02$ to 0.07$)$ \\
\hline Epidermoid & 3 & 3333 & . & 0.03 (0.01 to 0.06$)$ \\
\hline Unspecified neoplasm & 14 & 1111 & - & $0.09(0.03$ to 0.17$)$ \\
\hline $\begin{array}{l}\text { Any neoplastic incidental finding } \\
(\mathrm{n}=19559)\end{array}$ & ing 135 & 143 & 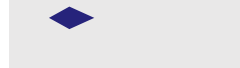 & $0.70(0.47$ to 0.98$)$ \\
\hline \multicolumn{5}{|c|}{ Structural vascular abnormalities ( $n=15559$ ) } \\
\hline Aneurysm & 67 & 286 & $\rightarrow$ & $0.35(0.13$ to 0.67$)$ \\
\hline Cavernous malformation & 23 & 625 & $=$ & $0.16(0.10$ to 0.23$)$ \\
\hline Arteriovenous malformation & 7 & 2000 & - & $0.05(0.01$ to 0.10$)$ \\
\hline \multicolumn{5}{|l|}{ Inflammatory lesions ( $\mathrm{n=15} 559$ ) } \\
\hline Definite demyelination & 9 & 1667 & - & $0.06(0.02$ to 0.15$)$ \\
\hline Possible demyelination & 4 & 3333 & . & $0.03(0.00$ to 0.07$)$ \\
\hline \multicolumn{5}{|l|}{ Cysts ( $n=15$ 559) } \\
\hline Arachnoid cyst & 99 & 200 & $\rightarrow-$ & $0.50(0.21$ to 0.87$)$ \\
\hline Colloid cyst & 2 & 2500 & . & 0.04 (0.01 to 0.07$)$ \\
\hline \multicolumn{5}{|l|}{ Other abnormalities ( $n=15559$ ) } \\
\hline Chiari I malformation & 71 & 417 & $\rightarrow-$ & 0.24 (0.04 to 0.58$)$ \\
\hline Hydrocephalus & 15 & 1000 & - & $0.10(0.03$ to 0.19$)$ \\
\hline Extra-axial collection & 4 & 2500 & . & 0.04 (0.01 to 0.07$)$ \\
\hline Any non-neoplastic incidental & 375 & 50 & & 2.00 (1.13 to 3.10$)$ \\
\hline * $(n=15559)$ & & & 0 & \\
\hline
\end{tabular}

Fig 1| Prevalence of some incidental findings ( ${ }^{\star}$ excluding white matter hyperintensities, microbleeds, and silent infarcts) on brain magnetic resonance imaging reports of two others with participants in just one 20 year age band. ${ }^{\text {w13 w16 }}$ No age specific data were available for children aged 0-9 years, and after omitting 34 adults aged 90-99, four 20 year age bands were left for analysis of age specific prevalence (fig 2). We analysed age specific data on white matter hyperintensities and silent brain infarcts (although these data were unavailable in some studies $^{\mathrm{w} 3 \mathrm{w} 10 \mathrm{w} 12 \mathrm{w} 16}$ ) simply to confirm that the data in the included studies showed known age specific trends in the prevalence of markers of cerebrovascular disease on brain MRI. ${ }^{6 \text { wl }}$

These grouped summary data showed an increasing prevalence with age for white matter hyperintensities $\left(\chi^{2}\right.$ for linear trend $\left.=71, \mathrm{P}<0.001\right)$ and silent brain infarcts $\left(\chi^{2}\right.$ for linear trend $\left.=104, \mathrm{P}<0.001\right)$, in keeping with the findings of other studies. ${ }^{6} \mathrm{w} 1$ The prevalence of neoplastic incidental brain findings also increased with age $\left(\chi^{2}\right.$ for linear trend $\left.=8.8, \mathrm{P}=0.003\right)$. The prevalence of non-neoplastic incidental brain findings, however, seemed to decline with age $\left(\chi^{2}\right.$ for linear trend $=6.9$, $\mathrm{P}=0.008$; fig 2), although this trend was reversed in a sensitivity analysis restricted to studies with age specific data that used at least one high resolution MRI sequence $\left(\chi^{2}\right.$ for linear trend $=66, \mathrm{P}<0.001$; see web extra appendix 2). ${ }^{\mathrm{w} 11 \mathrm{w} 12 \mathrm{w} 16}$

\section{DISCUSSION}

In this systematic review and meta-analysis of $16 \mathrm{stu}-$ dies totalling 19559 participants, the overall prevalence of incidental brain findings on brain MRI was $2.7 \%$ (number needed to scan=37). In studies where participants underwent at least one high resolution MRI sequence-as is common practice in research using brain imaging - the prevalence of incidental brain findings (excluding markers of cerebrovascular disease) was $4.3 \%$ (number needed to scan $=23$ ) compared with $1.7 \%$ (number needed to scan $=59$ ) in studies using only low resolution sequences, which are currently most commonly used in clinical practice. Alongside an expected age related trend in white matter hyperintensities and silent brain infarcts, we found an increasing prevalence of all neoplastic incidental brain findings with age (fig 2), probably driven by the increasing prevalence of meningiomas, ${ }^{\mathrm{w} 1}$ which were the most common neoplastic incidental brain finding (fig 1).

\section{Strengths and weaknesses of this review}

By synthesising all the published data on incidental brain findings and adding unpublished data where possible, we increased the precision of existing estimates of their prevalence across the whole age range and used a novel metric of the number needed to scan to detect one incidental finding (fig 1). We included data on all abnormalities, some of which were sought but not detected by smaller studies-for example, arteriovenous malformations and colloid cysts were not detected in a recent study. ${ }^{\mathrm{w} 1}$ The influence of variations in study design was diluted by pooling all the available data, and we were able to explore this heterogeneity in study characteristics and imaging sequences using 


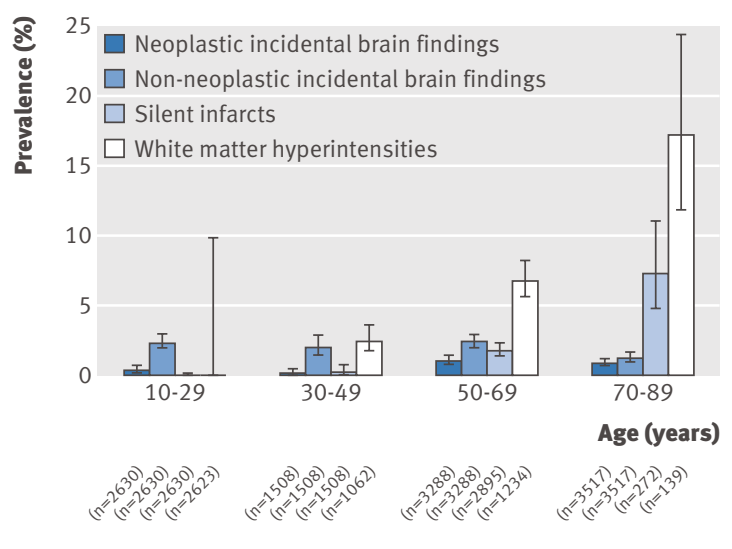

Fig 2 Prevalence of neoplastic incidental findings, nonneoplastic incidental findings, silent infarcts, and white matter hyperintensities, with $95 \%$ confidence intervals

subgroup analyses. The provision of some unpublished grouped summary data also enabled us to examine age specific prevalence.

Using only grouped summary data prevented us from exploring the influence of sex on the prevalence of incidental brain findings found in other studies. ${ }^{11 \mathrm{w} 7 \mathrm{w} 8}$ The proportion of participants who actually had neurological symptoms referable to apparently incidental brain findings was low $(0.1 \%)$; this may be unavoidable, however, because some participants may attend for covert investigation of undeclared symptoms, ${ }^{12}$ whereas others may be serial attenders checking on undeclared underlying disease. ${ }^{13}$ A general problem, particularly in research studies, is that many incidental brain findings are not reported in the study papers because such people are excluded at the point of recruitment, thereby potentially underestimating the true prevalence.

\section{Comparison with other studies}

Our pooled estimate provides a more precise summary of the existing data. The prevalence of incidental brain findings described by other studies has varied, in part because of the factors we have explored in sensitivity analyses. Reassuringly, the age related trends in silent brain infarcts and white matter hyperintensities that we observed were consistent with existing population based studies, ${ }^{6}$ which puts the other age related trends in context (fig 2 and web extra appendix 2). Others have found an increasing prevalence of some incidental brain findings with age, ${ }^{\text {w1 w6 w8 } 12}$ but we were able to classify them into neoplastic and non-neoplastic incidental findings (fig 2) and confirm the robustness of the trend in the prevalence of neoplastic incidental findings in a sensitivity analysis (see web extra appendix 2). One study has been published since we carried out our literature search, ${ }^{14}$ although it would have been difficult to include these data because the scanning parameters varied considerably during the study period.

Implications for clinical practice, research, and screening A major dilemma is whether to treat incidental brain findings and, if so, how. But the evidence is insufficient on what to do with most of them, partly because of the lack of controlled trials of their treatments and partly because the availability of MRI for only 20-30 years means that the long term prognosis is unknown. For example, the risk of haemorrhage from most unruptured aneurysms seems to be low $^{15}$ yet the risk of death and stroke from interventional treatment is sizeable. ${ }^{16}$ However, awareness of the presence of an unruptured intracranial aneurysm might lead to better modification of risk factors and potential benefits from interventional treatment. A randomised controlled trial is under way to address this dilemma (www.teamstudy. org). Treatment of unruptured brain arteriovenous malformations is independently associated with poor outcome in the short term, ${ }^{17}$ which has also led to an ongoing randomised controlled trial (www.arubastudy. org). Although repeated scanning has become commonplace for asymptomatic meningiomas, about $94 \%$ remain asymptomatic, about 63\% do not grow, and surgery carries a fair risk of morbidity, such that conservative management is generally recommended. ${ }^{18}$ Whether early treatment with surgery, radiotherapy, or chemotherapy improves symptom free survival for patients with low grade glioma is unknown. ${ }^{19}$

Some have suggested a subdivision of incidental brain findings by the perceived need and urgency of referral to a specialist. ${ }^{20}$ But the urgency of referral is difficult to gauge given the paucity of robust evidence about whether and how best to treat any of the asymptomatic incidental findings reported. The clinical urgency will vary according to the age and healthiness of the patient, and the perceived urgency may change over time as knowledge about the effects of treatment changes. ${ }^{14}$ This may explain why studies have variedfor example, some have classified arachnoid cysts as not requiring referral, ${ }^{\text {w7 }}$ whereas others have referred people with these cysts for urgent clinical assessment. ${ }^{\mathrm{w} 4}$ A preferable pragmatic approach is to manage imaging results with a degree of urgency on the basis of the likely overall benefit to the study participant. ${ }^{4}$

Apart from the harm that may arise from the lack of evidence on which to base the management of incidental brain findings, the detection of such findings can provoke considerable anxiety about a "possible abnormality" (which might be a false positive result) ${ }^{\text {w13}}$; involve a costly cascade of further investigations, with risks of complications (in the case of catheter angiography or brain biopsy); lead to costly medical opinions; and worry patients about the consequences of an untreated finding. For the patient, the discovery of an incidental brain finding may result in loss of their driving licence, life insurance, and even employment. ${ }^{21}$

The prevalence of incidental brain findings, the shortage of evidence on which to base their management, and the other harmful consequences of their discovery should provoke caution in a variety of settings. Clinicians should be cautious about investigations for reassuring patients because even the anxiolytic effects of having normal results on brain MRI are sustained for only a few months. ${ }^{22}$ At the very least clinicians 


\section{WHAT IS ALREADY KNOWN ON THIS TOPIC}

Brain magnetic resonance imaging (MRI) is widely used in research and clinical practice and can be purchased for health screening purposes

Brain MRI detects incidental findings in people with asymptomatic neurological conditions

Precise estimates of the frequency of incidental findings and influences on their detection are yet to be determined

\section{WHAT THIS STUDY ADDS}

The crude prevalence of incidental findings on brain MRI is $2.7 \%$, or one for every 37 neurologically asymptomatic people scanned

Incidental brain findings are more likely to be detected in studies using at least one high resolution MRI sequence than studies using standard sequences ( $4.3 \% \vee 1.7 \%)$

The frequency of incidental findings should be discussed when obtaining consent for brain $M R I$ in research and is relevant to clinical practice, but alone does not justify health screening

should counsel patients about the chance of incidental findings before requesting brain MRI. Volunteers for research studies using brain MRI should be informed of the chance and consequences of discovering an incidental abnormality, and research centres need to have mechanisms in place to deal with these once found. ${ }^{2}$ Furthermore, the increasing number of screening companies that provide "health check-ups" (especially in countries with widespread availability of brain $\mathrm{MRI},{ }^{323}$ has attracted caution from only a few regulatory bodies. ${ }^{2425}$ In such screening the actual objective is the discovery of incidental brain findings, which may be regarded by the client as fortuitous. ${ }^{312}$ Although true negative results from brain MRI may be reassuring, many of the requirements of a screening test are not fulfilled; most of all, the overall benefit of such screening on quality adjusted life years is unproved. The cost effectiveness of screening using brain MRI also seems unfavourable: in a study in Japan the cost for the identification of one person with an incidental abnormality requiring further evaluation was \$24 733 (£14994; €17389), ${ }^{\text {w10 }}$ and screening is not even thought to be cost effective for some of the more worrying incidental brain findings such as aneurysm ${ }^{26}$ and silent brain infarcts. ${ }^{6}$ Consequently, guidance from professional organisations such as the American Heart Association has cautioned against screening the general population for particular conditions, such as intracranial aneurysms. ${ }^{27}$ People purchasing a health check-up brain MRI from a screening company should be able to consider the consequences on the basis of clear information about the prevalence of incidental findings and the potentially detrimental effects of discovering them, ${ }^{28}$ especially in the light of a recent review of direct to consumer marketing information in the United States, most of which failed to provide comprehensive balanced information, including the risks of having a scan. ${ }^{29}$

\section{Implications for future research}

A meta-analysis of studies on incidental brain findings using individual patient data is the only way to disentangle the various influences that we have found on prevalence, including characteristics of the participants, the imaging sequences used, and who reports them. For example, reporting age specific data will help confirm the age related trends described in this review. Furthermore, future studies of the prevalence of incidental brain findings would benefit from definitions and normal variants being prespecified.

Guidance on the wide variety of ethical issues concerning the participation of healthy volunteers in brain imaging research is beginning to emerge. ${ }^{2430}$ In future studies, volunteers should be provided with accurate information on the prevalence of incidental brain findings as part of the informed consent process, pointing out the higher detection in studies using high resolution MRI sequences. A mechanism for dealing with potential abnormalities that is appropriate to the research setting should be in place. ${ }^{2}$

\section{Conclusions}

Doctors who request scans in clinical practice or who recommend screening for health check-ups, and researchers who obtain consent from volunteers, should provide information about the prevalence of incidental brain findings on brain MRI, the higher prevalence with high resolution MRI sequences, and the shortage of evidence to inform their management.

We thank the Edinburgh Stroke Research Group for its comments. Contributors: RA-SS, WW, CPW, JMW, and ZM conceived and designed the study. ZM, WW, and RA-SS collected and analysed the data. WTL, FW Y-CL, YT, HA, and SCL extracted and contributed additional grouped summary data from studies included in this review. RA-SS, ZM, and WW wrote the paper. All authors had full access to the data in the study, can take responsibility for the integrity of the data and the accuracy of the data analysis, and edited and approved the final version. RA-SS is the guarantor

Funding: The Chief Scientist Office of the Scottish Government supports WW with a Clinical Academic Training Fellowship, and ZM with a research and development infrastructure award for radiology to Lothian

Universities Hospitals NHS Trust Research and Development Office. The UK Medical Research Council supports RA-SS with a clinician scientist fellowship. JMW is partly supported by the Scottish Funding Council and Chief Scientist Office through the SINAPSE (Scottish Imaging Network. A Platform for Scientific Excellence) Collaboration (www.sinapse.ac.uk). The Cardiovascular Health Study is funded by the National Heart, Lung, and Blood Institute. The researchers are independent of the funders, and the study sponsors had no role in the study design; the collection, analysis, and interpretation of data; the writing of the report; and the decision to submit the article for publication.

Competing interests: None declared.

Ethical approval: Not required.

1 Peterson CL, Burton R. US health care spending: comparison with other OECD countries. 15. Congressional Research Service. CRS Report for Congress, 2007.

2 Illes J, Kirschen MP, Edwards E, Bandettini P, Cho MK, Ford PJ, et al. Practical approaches to incidental findings in brain imaging research. Neurology 2008;70:384-90.

3 Al-Shahi Salman R, Whiteley WN, Warlow C. Screening using wholebody magnetic resonance imaging scanning: who wants an incidentaloma? J Med Screen 2007;14:2-4

4 Wolf SM, Lawrenz FP, Nelson CA, Kahn JP, Cho MK, Clayton EW, et al. Managing incidental findings in human subjects research: analysis and recommendations. J Law Med Ethics 2008;36:219-48.

5 Cordonnier C, Al-Shahi Salman R, Wardlaw J. Spontaneous brain microbleeds: systematic review, subgroup analyses and standards for study design and reporting. Brain 2007;130:1988-2003.

6 Vermeer SE, Longstreth Jr WT, Koudstaal PJ. Silent brain infarcts: a systematic review. Lancet Neurol 2007;6:611-9.

7 DerSimonian R, Laird N. Meta-analysis in clinical trials. Control Clin Trials 1986;7:177-88. 
8 Weber F, Knopf H. Cranial MRI as a screening tool: findings in 1,772 military pilot applicants. Aviation Space Environment Med 2004;75:158-61.

9 Göhde SC, Goyen M, Forsting M, Debatin JF. [Prevention without radiation-a strategy for comprehensive early detection using magnetic resonance tomography]. [German]. Radiologe 2002;42:622-9.

10 Meadows J, Kraut M, Guarnieri M, Haroun RI, Carson BS. Asymptomatic Chiari type I malformations identified on magnetic resonance imaging. J Neurosurg 2000;92:920-6.

11 Sawamura Y, Ikeda J, Ozawa M, Minoshima Y, Saito H, Abe H. Magnetic resonance images reveal a high incidence of asymptomatic pineal cysts in young women. Neurosurgery 1995;37:11-5.

12 Mamourian A. Incidental findings on research functional MR images: should we look? A/NR Am / Neuroradiol 2004;25:520-2.

13 Pickard JD, Gillard JH. Guidelines reduce the risk of brain-scan shock. Nature 2005;435:17.

14 Hoggard N, Darwent G, Capener D, Wilkinson ID, Griffiths PD. The high incidence and bioethics of findings on magnetic resonance brain imaging of normal volunteers for neuroscience research. J Med Ethics 2009;35:194-9.

15 Wiebers DO, Whisnant JP, Huston J, III, Meissner I, Brown RD Jr, Piepgras DG, et al. Unruptured intracranial aneurysms: natural history, clinical outcome, and risks of surgical and endovascular treatment. Lancet 2003;362:103-10.

16 Lanterna LA, Tredici G, Dimitrov BD, Biroli F. Treatment of unruptured cerebral aneurysms by embolization with guglielmi detachable coils: case-fatality, morbidity, and effectiveness in preventing bleeding-a systematic review of the literature. Neurosurgery 2004;55:767-75.

17 Wedderburn CJ, van Beijnum J, Bhattacharya JJ, Counsell CE, Papanastassiou V, Ritchie V, et al. Outcome after interventional or conservative management of unruptured brain arteriovenous malformations: a prospective, population-based cohort study. Lancet Neurol 2008;7:223-30.

18 Yano S, Kuratsu J, Kumamoto Brain Tumor Research Group. Indications for surgery in patients with asymptomatic meningiomas based on an extensive experience. J Neurosurg 2008;105:538-43.

19 Cavaliere R, Lopes MB, Schiff D. Low-grade gliomas: an update on pathology and therapy. Lancet Neurol 2005;4:760-70.
20 Bryan RN, Manolio TA, Schertz LD, Jungreis C, Poirier VC, Elster AD, et al. A method for using MR to evaluate the effects of cardiovascular disease on the brain: the cardiovascular health study. AJNR Am J Neuroradiol 1994;15:1625-33.

21 Piatt JH Jr. Unexpected findings on brain and spine imaging in children. Pediatr Clin North Am 2004;51:507-27.

22 Howard L, Wessely S, Leese M, Page L, McCrone P, Husain K, et al. Are investigations anxiolytic or anxiogenic? A randomised controlled trial of neuroimaging to provide reassurance in chronic daily headache. J Neurol Neurosurg Psychiatry 2005;76:1558-64.

23 Komotar RJ, Starke RM, Connolly ES. Brain magnetic resonance imaging scans for asymptomatic patients: role in medical screening. Mayo Clin Proc 2008;83:563-5.

24 Health Canada. Whole body screening using MRI or CT technology. Ottawa, ON; Health Canada, 2003.

25 Royal Australian and New Zealand College of Radiologists. The use of diagnostic imaging for screening purposes and non-referred investigations: RANZCR statement of principles. Sydney, Australia: RNAZCR, 2005.

26 Yoshimoto Y, Wakai S. Cost-effectiveness analysis of screening for asymptomatic, unruptured intracranial aneurysms. A mathematical model. Stroke 1999;30:1621-7.

27 Bederson JB, Awad IA, Wiebers DO, Piepgras D, Haley EC Jr, Brott T, et al. Recommendations for the management of patients with unruptured intracranial aneurysms: a statement for healthcare professionals from the Stroke Council of the American Heart Association. Stroke 2000;31:2742-50.

28 Entwistle VA, Carter SM, Trevena L, Flitcroft K, Irwig L, McCaffery K, et al. Communicating about screening. BMJ 2008;337:a1591.

29 Illes J, Kann D, Karetsky K, Letourneau P, Raffin TA, Schraedley-Desmond $\mathrm{P}$, et al. Advertising, patient decision making, and self-referral for computed tomographic and magnetic resonance imaging. Arch Intern Med 2004;164:2415-9.

30 Seixas D, Ayres Basto M. Ethics in fMRI studies. A review of the EMBASE and MEDLINE literature. Clin Neuroradiol 2008;18:79-87.

Accepted: 27 May 2009 